Www.jmscr.igmpublication.org

Impact Factor (SJIF): 6.379

Index Copernicus Value: 79.54

ISSN (e)-2347-176x ISSN (p) 2455-0450

crossrefDOI: https://dx.doi.org/10.18535/jmscr/v6i12.185

Journal Of Medical Science And Clinical Research

IGM Publication

An Official Publication of IGM Publication

\title{
Surveillance of Hypertensions in pregnant women: Our experience
}

Authors

\section{Deepak Kumar Parhi, Kumar Gaurav Behera*}

Department of Cardiology, IMS and SUM Hospital, Siksha O Anusandhan University,

K 8, Kalinga Nagar, Bhubaneswar-751003, Odisha, India

*Corresponding Author

Dr Gaurav Behera

Assistant Professor, Department of Cardiology, IMS and SUM Hospital, Bhubaneswar-751003, Odisha, India

Email: kumargauravbehera@soa.ac.in

\section{Abstract}

Study objective: Our motivation was to think about the connection among wheezing and pregnancyinitiated hypertension and development impediment of the baby. Plan: Retrospective, cross-sectional, back to back case arrangement.

Materials and Methods: The Department of Cardiology, IMS and SUM Hospital, Bhubaneswar. Members and estimations: upon the arrival of conveyance, 502 ladies with singleton pregnancies finished a survey about wheezing, saw rest apneas, and daytime weakness. Information concerning restorative intricacies were taken from the ladies' casebooks.

Results: Amid the most recent seven day stretch of pregnancy, 23\% of the ladies revealed wheezing each night. Just $4 \%$ detailed wheezing before getting to be pregnant. Hypertension created in $14 \%$ of wheezing ladies, contrasted and $6 \%$ of nonsnorers $(p<0.01)$. Preeclampsia happened in $10 \%$ of snorers, contrasted and $4 \%$ of nonsnorers ( $p<0.05)$. An Apgar score $<7$ was increasingly basic in newborn children destined to constant snorers. Development impediment of the baby, characterized as little for gestational age during childbirth, had happened in $7.1 \%$ of the babies of wheezing moms and $2.6 \%$ of the rest of the newborn children $(p<0.05)$. Ongoing wheezing was autonomously prescient of hypertension (chances proportion $[O R], 2.03 ; p<0.05)$ and development hindrance $(O R, 3.45 ; p<0.01)$ in a calculated relapse investigation controlling for weight, age, and smoking.

Conclusions: Wheezing is regular in pregnancy and is an indication of pregnancy-initiated hypertension. Wheezing shows a danger of development impediment of the embryo.

Keywords: hypertension; intrauterine growth retardation; preeclampsia; pregnancy; small for gestational age; snoring.

\section{Introductions}

Preeclampsia, characterized as pregnancyprompted hypertension and proteinuria, as often as possible joined with edema, is asymptomatic in a few ladies yet may instigate serious side effects in others. ${ }^{1}$ Hypertensive scatters amid pregnancy are a main source of maternal passing in the United States and Great Britain ${ }^{1,2}$ and are critical reasons for neonatal morbidity and mortality., ${ }^{3,4}$ The reason for these infections is, be that as it may, in 
any case obscure. The examination was bolstered by gifts from the Swedish Heart and Lung Foundation and the Swedish Association for Heart and Lung Patients. Composition got November 20, 1998; amendment acknowledged August 16, 1999 Wheezing is an indication of expanded upper aviation route opposition and obstructive rest apnea, ${ }^{5-7}$ which is related with blood vessel hypertension and coronary supply route dis-ease. ${ }^{8}$

${ }^{-10}$ Muscle thoughtful nerve action and noc-turnal norepinephrine levels are raised in these patients and are viewed as a conceivable reason for rest apnea-instigated hypertension. ${ }^{11,12}$

Wheezing and rest apnea are frequently caused by elements that thin the upper aviation route. Both nasal blockage and pharyngeal edema are such tighten ing factors happening amid pregnancy. ${ }^{13}$ However, just a couple of case reports including rest apnea and inconveniences amid pregnancy are available. ${ }^{14-17}$ One of these reports identifies with an instance of intrauterine development retardation, ${ }^{15}$ and one depicts a lady with preeclampsia. $^{17}$ Loube et $\mathrm{al}^{18}$ detailed that wheezing recurrence increments amid pregnancy, yet nobody has researched in the case of wheezing is related with hypertensive issue of pregnancy.

In the present examination, we researched the association of self-revealed wheezing with confusions of pregnancy and fetal result.

\section{Materials and Methods}

The investigation was performed at the Department of Obstetrics and Gynecology at IMS and SUM Hospital, Bhubaneswar. A survey was controlled by four birthing specialists to 518 sequential ladies upon the arrival of conveyance. Ladies who experienced cesarean segment and the individuals who brought forth a dead child or twins were excluded. Everything except 16 ladies finished the surveys. Complete answers were in this way gotten from 502 ladies with singleton pregnancies. The ladies had a mean load of 74.5 " $12.0 \mathrm{~kg}$, and they were 28.9 " 5.0 years old at conveyance. Everything except 10 ladies were white and were conceived either in Sweden or Finland.

\section{Questionnaire}

At the point when a lady addressed the survey she was, principle speaking, joined by her accomplice. The poll was administered when she entered the doctor's facility upon the arrival of conveyance. She was requested to rate her wheezing recurrence before pregnancy and amid the most recent week before conveyance as indicated by a five-point scale comparing to never, sometimes, at times, frequently, or dependably. She was additionally gotten some information about the time amid the pregnancy when the wheezing started. Routine wheezing was considered if wheezing recurrence was appraised as regularly or dependably at the day of conveyance.

Intemperate daytime tiredness was characterized as an answer of "Truly, a ton" to the inquiry, "Did you encounter over the top daytime languor amid the pregnancy?" The other conceivable answers were, "No, it was of course" or "No, I turned out to be progressively alert amid the pregnancy."

The inquiries likewise identified with smoking propensities, drug, and attendant illness. Her accomplice was inquired as to whether he had noted apneas amid rest. They were both solicited to coordinate on inquiries from wheezing and saw rest apneas.

\section{BP measurements}

The BP estimations were recorded in every lady's drug ical outline. The majority of the considered ladies had gone to the pre-birth center where examinations, incorporating BP estimations in the recumbent position, were made at gestational weeks $8-10,12,25,28,31,33,35,37,39$, and 41. Follow-up BP estimations were recorded all the more much of the time when an expanded BP was watched.

\section{Complications}

The ladies' edema was appraised from 0 to 3, and their body weight was recorded before 
conveyance. Information concerning medicinal inconveniences were taken from the ladies' casebooks.

Chronicles were acquired from the newborn children's introduction to the world weight, length, sex, head size, and Apgar score at 1 and 5 min after birth. The Apgar score depended on pulse, respiratory exertion, muscle tone, reflex peevishness, and skin color.19 Each factor was evaluated from 0 to 2 , where 2 was typical. The greatest Apgar score was 10.

\section{Definitions}

Pregnancy-initiated hypertension was characterized as rehashed BP chronicles \# 140/90 $\mathrm{mm} \mathrm{Hg}$ showing up amid the pregnancy.

Four ladies had hypertension before the pregnancy and were, consequently, not respected to experience the ill effects of pregnancy-instigated hypertension. Preeclampsia was characterized as pregnancy-prompted hypertension with proteinuria ! $0.3 \mathrm{~g} / 24 \mathrm{~h}$. Development hindrance of the hatchling was viewed as when the baby was little for gestational age as per a birth load underneath 2 SDs on the Swedish standard chart.20

\section{Statistical Analysis}

The information are exhibited as mean " SD for nonstop factors and as rates for ostensible qualities. Contrasts between two methods were surveyed utilizing Student's $t$ test for free examples. Contrasts between extents were dissected utilizing the \$2 test. Fisher's twofollowed Exact Test was utilized when proper. Multiple strategic relapse was utilized to dissect the connection among wheezing and entanglements of pregnancy. The invalid theory was rejected at the 5\% level ( $\mathrm{p} \% 0.05$ ).

\section{Results}

Wheezing recurrence expanded amid pregnancy (p \% 0.001). Of the absolute example, $7 \%$ of the pregnant ladies expressed that they began to wheeze or extraordinarily expanded their wheezing recurrence amid the principal trimester, $6 \%$ amid the second trimester, and 24\% amid the third trimester. Ongoing wheezing appraised as consistently or pretty much consistently was accounted for by $23 \%$ of the pregnant ladies amid the most recent week before conveyance. Infrequent wheezing was accounted for by another $25 \%$. Just $4 \%$ of the ladies revealed that they had wheezed constantly, and $22 \%$ wheezed occasionally before getting to be pregnant.

Seen rest apneas were seen in $11 \%$ of constant snorers, as contrasted and $2 \%$ of the non-routine snorers ( $\mathrm{p} \%$ 0.001). Ladies who wheezed constantly had a mean load of 64.1 " $14.3 \mathrm{~kg}$ before getting to be pregnant, which was more than the rest of the ladies, who weighed 59.5 " $10.3 \mathrm{~kg}$ (p ! 0.002). The routinely wheezing ladies likewise had a progressively articulated weight increment amid pregnancy ( $\mathrm{p} \%$ 0.05) and were marginally more established than the rest ( $\mathrm{p} \%$ 0.05; Table 1).

\section{Preeclampsia and Pregnancy-Induced Hypertension}

Fourteen percent of the ladies who wheezed habitually had pregnancy-actuated hypertension as contrasted and $6 \%$ of the nonsnorers (p \% 0.01). $10 \%$ of the ladies who wheezed met the meaning of preeclampsia with hypertension and proteinuria as contrasted and $4 \%$ of the nonsnorers ( $p \%$ 0.05). Every one of the patients with preeclampsia who wheezed constantly amid the most recent seven day stretch of pregnancy had begun to wheeze amid the pregnancy and before any indication of preeclampsia was available.

Seen rest apneas would in general be more frequent in ladies with preeclampsia (p ! 0.069) and pregnancy-prompted hypertension ( $\mathrm{p} !$ 0.055). They were accounted for in $12 \%$ of ladies with preeclampsia and $10 \%$ of ladies with hypertension. 
Table 1

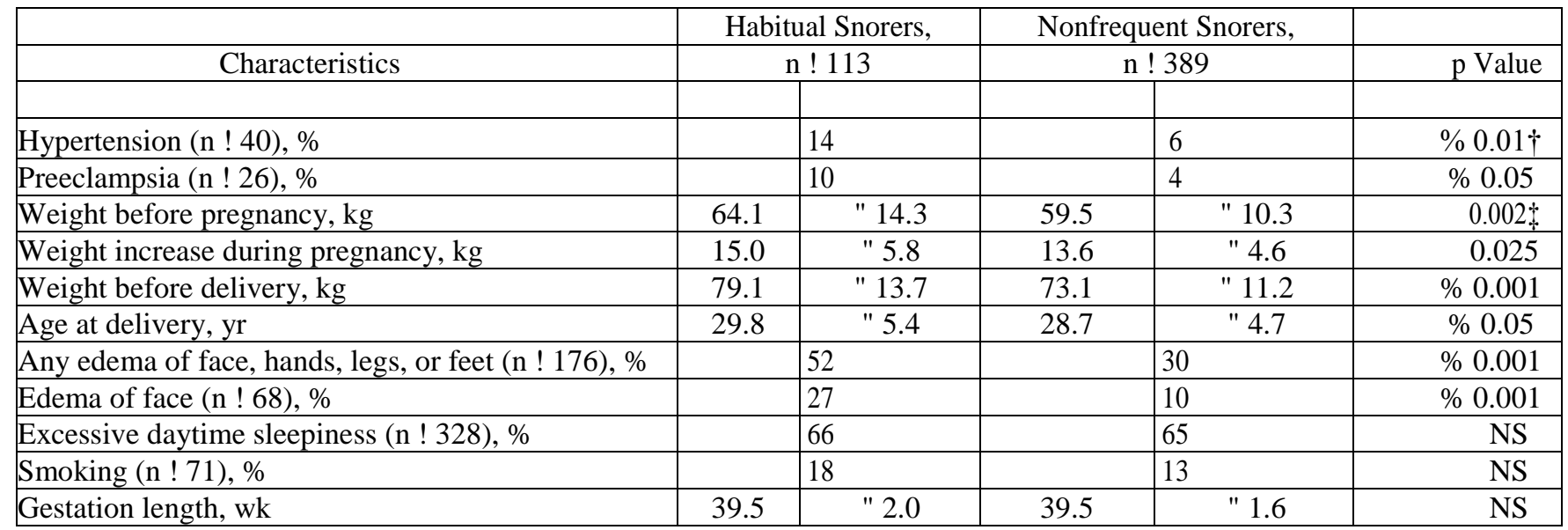

Routine wheezing was a hazard factor, free of weight, age and smoking propensities, for pregnancy-incited hypertension (chances proportion [OR], 2.03; p \% 0.05) and furthermore tended, however not altogether, to be an autonomous hazard factor for preeclampsia (OR, $2.18 ; \mathrm{p} ! 0.07)$ as indicated by the numerous calculated relapse investigation (Table 2).

\section{Excessive Daytime Sleepiness}

Unreasonable daytime lethargy was abstractly reported in the same number of as $65 \%$ of the ladies. It began amid the main trimester in $25 \%$ of the ladies, amid the second trimester in $18 \%$, and amid the third trimester in $22 \%$. The predominance of exorbitant daytime drowsiness was comparative among ladies who wheezed constantly and among the individuals who did not (Table 1). All in all, daytime languor began prior in pregnancy than did wheezing.

\section{Edema}

Edema was overrepresented among women who snored habitually. Edema of the face, hands, legs, or feet occurred in $52 \%$ of the habitual snorers com- pared with $30 \%$ of the remainder (p \% 0.001 ). Facial edema was observed in $27 \%$ of the habitual snorers, compared with $10 \%$ of the remaining women ( $\mathrm{p} \%$ 0.001).
Table 2

\begin{tabular}{|l|c|c|c|}
\hline \multicolumn{1}{|c|}{ Characteristics } & OR & $95 \%$ CI & p Value \\
\hline Habitual snoring & 2.03 & $1.01-4.10$ & $\% 0.05$ \\
\hline Smoking & 1.06 & $0.42-2.69$ & NS \\
\hline $\begin{array}{l}\text { Weight before delivery } \\
(\mathrm{kg})\end{array}$ & 1.02 & $1.00-1.05$ & 0.08 \\
\hline Age at delivery (yr) & 1.06 & $0.99-1.13$ & 0.09 \\
\hline
\end{tabular}

\section{Infant Outcome}

Eight of the 113 habitual snorers (7.1\%) delivered an infant with growth retardation at birth (small for gestational age), compared with 10 of 379 of the nonhabitual snorers $(2.6 \% ; \mathrm{p} \% 0.05)$. Snoring remained as a significant predictor of growth retarda-tion (OR, 3.45; p \% 0.01) in the multiple logistic regression after adjustment for weight, age, and smoking habits (Tables 3, 4). Smoking was also found to be an independent predictor of growth retardation (OR, 3.94; $\mathrm{p} \%$ 0.01).

An Apgar score " 7 was more common in infants born to habitual snorers compared with infants born to occasional snorers and nonsnorers, 1 and 5 min after delivery (Table 3).

Table 3

\begin{tabular}{|c|c|c|c|}
\hline & Habitual & $\begin{array}{c}\text { Nonfrequ } \\
\text { ent }\end{array}$ & \\
\hline & Snorers, & Snorers, & \\
\hline Characteristics & $\mathrm{n} ! 113$ & $\mathrm{n} ! 389$ & $\mathrm{p}$ \\
Value
\end{tabular}


Table 4

\begin{tabular}{|l|c|r|l|}
\hline \multicolumn{1}{|c|}{ Characteristics } & OR & $95 \%$ CI & p Value \\
\hline & & & \\
\hline Habitual snoring & 3.45 & $1.26-9.42$ & $\% 0.01$ \\
\hline Smoking & 3.94 & $1.45-10.72$ & $\% 0.01$ \\
\hline $\begin{array}{l}\text { Weight before delivery } \\
\text { (kg) }\end{array}$ & 0.96 & $0.92-1.01$ & 0.09 \\
\hline Age at delivery (yr) & 0.99 & $0.90-1.10$ & NS \\
\hline
\end{tabular}

Habitual snoring did not influence the ratio of birth weight to placenta weight. Witnessed sleep apneas of the mother did not relate to infant outcome.

\section{Discussion}

In the present examination, constant wheezing amid pregnancy was identified with hypertension, preeclampsia, edema, and expanded body weight. Ongoing wheezing in the mother was additionally connected with development impediment of the hatchling and a low Apgar score for the newborn child. Routine wheezing was autonomously prescient of hypertension and development impediment, notwithstanding when weight, age, and smoking were controlled for.

Wheezing might be viewed as a typical element of pregnancy, as $23 \%$ of the ladies in this investigation wheezed constantly and $25 \%$ wheezed every so often, though just $4 \%$ had wheezed routinely before pregnancy. Loube et al ${ }^{18}$ found that routine wheezing happened in $14 \%$ of pregnant ladies ( $\mathrm{n}$ ! 350). The ladies addressed the survey upon the arrival of conveyance in the present investigation, and not amid the second or third trimester just like the case in the examination by Loube et $\mathrm{al}^{18}$ They didn't discover any impact on the babies, while we found an expanded recurrence of newborn children brought into the world little for gestational age.

The expanded recurrence of newborn children brought into the world little for gestational age and low Apgar scores in the babies of wheezing moms is a novel finding. It demonstrates that the outcomes of expanded upper aviation route resistance amid rest may influence the baby and backings the recently recommended connection between rest apnea and intrauterine development retardation. $^{15}$

The relationship among wheezing and pregnancyactuated hypertension and preeclampsia is additionally a novel finding that has not recently been examined. It is beyond the realm of imagination to expect to make any firm inferences about the circumstances and logical results as a result of the present examination plan. Be that as it may, the majority of the subjects who wheezed constantly and had preeclampsia begun to wheeze before any indication of hypertension or proteinuria was available, and routine wheezing was identified with mind nessed rest apneas. This demonstrates nighttime upper aviation route check may add to the advancement of pregnancy-incited hypertension and preeclampsia. It is conceivable that pregnant ladies are particularly powerless against increments in upper aviation route opposition, as breathing may likewise be limited by an expansion in the stomach weight influencing the stomach. Respiratory rest contemplates, including the treatment of rest apnea in ladies with preeclampsia, are alluring and may answer the topic of whether there is an etiologic connection be-tween expanded upper aviation route opposition and preeclampsia.

Aside from wheezing, extreme daytime tiredness is the most well-known indication of obstructive rest apnea. ${ }^{21}$ A lion's share of the present ladies revealed that they had encountered over the top daytime sleepiness amid the pregnancy. It was not, be that as it may, overrepresented among the individuals who wheezed constantly, and sluggishness regularly started before in pregnancy than wheezing. Like our discoveries, Loube et al18 couldn't discover any connection between daytime lethargy and wheezing in pregnant ladies utilizing the Epworth languor scale. Despite what might be expected, they revealed that the Epworth sluggishness score was the equivalent for pregnant and non pregnant ladies. Regardless of whether over the top daytime tiredness is initiated by pregnancy is as yet misty. In any case, all things considered, grumblings of daytime weakness and 
sluggishness amid pregnancy are because of variables other than bothered rest because of wheezing.

Wheezing is the capable of being heard indication of an expansion in upper aviation route obstruction. In this examination, the wheezing frequency relied upon the degree to which the bed-room accomplice saw it. There is no global agreement on the target meaning of wheezing, albeit target chronicles utilizing amplifiers connect well with abstract wheezing in youthful adults. ${ }^{22}$ Subjective reports are, notwithstanding, the most usually utilized instrument for estimating wheezing, halfway in view of the specialized issues required with receiver accounts and somewhat in light of the fact that the emotional reports give a normal of the subject's level of wheezing, while the aftereffect of the record-ing of a solitary night might delude.

A restriction with cross-sectional reviews is that it is beyond the realm of imagination to expect to reach any inferences in regards to the reason and the impact. A puzzling impact of an uncontrolled factor could have been in charge of the present outcomes despite the fact that wheezing has all the earmarks of being a hazard factor. Conceivable jumbling factors not controlled for in the present investigation were, for instance, the weight record, the equality, and the societal position. Another restriction is that wheezing depended on emotional reports. Be that as it may, this is an issue likewise in other epidemiologic investigations of wheezing.

Ladies who detailed ongoing wheezing were heavier before pregnancy and put on more load amid pregnancy. Edema was progressively basic in constant snorers. It might be conjectured that pharyngeal swelling could limit the upper aviation route to a basic time when wheezing would happen. Weight gain and pharyngeal edema are accordingly conceivable reasons for pregnancyinstigated wheezing. Nasal conges-tion because of hormonal changes may, notwithstanding, additionally have added to wheezing, since $7 \%$ detailed that they began to wheeze amid the primary trimester.

Wheezing is normal in pregnancy and is an indication of pregnancy-incited hypertension. Wheezing demonstrates a danger of development impediment of the hatchling.

\section{References}

1. Wallenburg HCS. Detecting hypertensive disorders of preg-nancy. In: Chalmers I, Enkin M, Keirse MJNC, eds. Effective care in pregnancy and childbirth. Oxford, UK: University Press, 1989; 382- 402

2. Kaunitz AM, Hughes JM, Grimes DA, et al. Causes of maternal mortality in the United States. Obstet Gynecol 1985; 65:605- 612

3. Chamberlain G, Phillip E, Howlett B, et al. British births 1970: Vol 2. Obstetric care. London, UK: Heinemann, 1978; $80-107$

4. MacGillivray I. Pre-eclampsia: the hypertensive disease of pregnancy. London, UK: WB Saunders, 1983

5. Gislason T, Benediktsdo' ttir B, Bjo“ rnsson JK, et al. Snoring, hypertension, and the sleep apnea syndrome: an epidemiologic survey of middle-aged women. Chest 1993; 103:1147-1151

6. Guilleminault C, Stoohs R, Duncan S. Snoring (1): daytime sleepiness in regular heavy snorers. Chest 1991; 99:40 - 48

7. Bliwise DL, Nekich JC, Dement WC. Relative validity of self-reported snoring as a symptom of sleep apnea in a sleep clinic population. Chest 1991; 99:600 608

8. Hla KM, Young TB, Bidwell $\mathrm{T}$, et al. Sleep apnea and hypertension: a population-based study. Ann Intern Med 1994; 120:382-388

9. Franklin KA, Nilsson J, Sahlin C, et al. Sleep apnoea and nocturnal angina. Lancet 1995; 345:1085-1087

10. Mooe T, Rabben T, Wiklund U, et al. Sleep-disordered breathing in women: 
occurrence and association with coro-nary artery disease. Am J Med 1996; 101:251256.

11. Carlson JT, Hedner J, Elam M, et al. Augmented resting sympathetic activity in awake patients with obstructive sleep apnea. Chest 1993; 103:1763-1768

12. Lapinski M, Przybylowski T, Lewandowski J, et al. Diurnal blood pressure rhythm and urinary catecholamine excretion in obstructive sleep apnoea and essential hypertension. J Hy-pertens 1993; 11(Suppl 5):292-293

13. Pilkington S, Carli F, Dakin MJ, et al. Increase in Mallampati score during pregnancy. Br J Anaesth 1995; 74:638 642

14. Joel-Cohen SJ, Schoenfeld A. Fetal response to periodic sleep apnea: a new syndrome in obstetrics. Eur J Obstet Gynecol Reprod Biol 1978; 8:77-81

15. Charbonneau M, Falcone T, Cosio MG, et al. Obstructive sleep apnea during pregnancy: therapy and implications for fetal health. Am Rev Respir Dis 1991; 144:461- 463

16. Sherer DM, Caverly CB, Abramowicz JS. Severe obstructive sleep apnea and associated snoring documented during external tocography. Am J Obstet Gynecol 1991; 165:1300 - 1301

17. Lefcourt LA, Rodis JF. Obstructive sleep apnea in pregnancy. Obstet Gynecol Surv 1996; 51:503-506

18. Loube MDI, Poceta JS, Morales MC, et al. Self-reported snoring in pregnancy: association with fetal outcome. Chest 1996; 109:885-889

19. Fisher DE, Paton JB. Resuscitation of the newborn infant In: Klaus MH, Fanaroff AA, eds. Care of the high-risk neonate. Philadelphia, PA: WB Saunders, 1986; 35-37
20. Marsal K, Persson P-H, Larsen T, et al. Intrauterine growth curves based on ultrasonically estimated fetal weights. Acta Paediatr 1996; 85:843- 88

21. Lavie P. Incidence of sleep apnea in a presumably healthy working population: a significant relationship with excessive daytime sleepiness. Sleep 1983; 6:312-318

22. Stoohs RA, Blum H-C, Haselhorst M, et al. Normative data on snoring: a comparison between younger and older adults. Eur Respir J 1998; 11:451- 457. 